\title{
Multiscale Analysis of the Interfacial Mechanical Behavior for Composite of Carbon Nanotube and $\alpha$-Alumina
}

\author{
Tingting Yan and Gaofeng Wei \\ School of Mechanical and Automotive Engineering, Qilu University of Technology, Jinan 250353, China \\ Correspondence should be addressed to Gaofeng Wei; weigaofeng@126.com
}

Received 4 December 2013; Accepted 10 April 2014; Published 16 June 2014

Academic Editor: Gonzalo Martínez-Barrera

Copyright (C) 2014 T. Yan and G. Wei. This is an open access article distributed under the Creative Commons Attribution License, which permits unrestricted use, distribution, and reproduction in any medium, provided the original work is properly cited.

\begin{abstract}
Based on multiscale methods the mechanical behavior for the interface of carbon nanotube and $\alpha$-alumina is analyzed. The stress transfer between nanotube and alumina is provided by van der Waals interaction. Using cohesive law the relationship between normal stress (shear stress) and displacement is studied, as well as the stress intensity. The stress distribution of the interface is obtained by improved COX model. The strain rate of nanotube-composite is presented when the interfacial slip occurs through the van der Waals interaction.
\end{abstract}

\section{Introduction}

The main goal of computational materials science is the rapid and accurate prediction of properties of new materials before their development and production. In order to develop new materials and composites with designed new properties, it is essential that these properties can be predicted before preparation, processing, and characterization.

In recent years, a new field in the improvement of ceramic brittle has been opened up by using short fiber as the reinforcement, and there are more and more experiments and theoretical research publishing the toughening effect by using carbon nanotube (CNTs) as the ceramic reinforcement [14]. However, carbon nanotubes do not bond well to ceramic, and their interactions are due to van der Waals force, which is much weaker than covalent bonds. This leads to sliding of CNTs in the ceramic-matrix when subjected to loading.

Nanocomposites possess a large amount of interfaces due to the small size of reinforcements. The interface behavior can significantly affect the mechanical properties of nanocomposites. Chowdhury and Okabe [5] studied the mechanical behavior of the interface of CNTs and polymer by using molecular dynamics method that there are chemical crosslinks in it. Chen et al. [6] analyzed the failure mode and designed optimal toughness of carbon nanotube-reinforced composites when there is chemical bond in the interface.
Liu et al. [7] used the pull-out model which, based on both van der Waals and electrostatic interaction, numerically studied the interfacial mechanical behavior of CNTs and alumina, but this method is limited to temporal and spatial scales and can only be used to solve the fraction of the interfacial mechanical behavior.

Both Jiang et al. $[8,9]$ and $\mathrm{Lu}$ et al. $[10,11]$ established the nonlinear cohesive law for the CNT/polymer interfaces directly from the Lennard-Jones potential for van der Waals interactions. Chen et al. [12] used COX model to analyse the interfacial characteristics of CNTs reinforced aluminum oxide nanocomposites. Xiao and Zhang [13] analyzed the stress transfer efficiency of a single-walled carbon nanotube in epoxy matrix and manifested that a smaller tube diameter has a more effective reinforcement and there exists an optimal tube length at which reinforcement is maximized, and there is a greater stress transfer efficiency compared with solid fiber.

In this paper, a micromechanics model is provided to predict the interfacial behavior of multiwall carbon nanotubes (MWCNTs) and the crystal lattice structure of $\alpha$ alumina since MWCNTs are widely used as reinforcements in nanocomposites. The van der Waals interactions between a carbon atom and a $\alpha-\mathrm{AlO}_{2}$ unit are given, as well as between a pair of carbon atoms. The effect of MWCNT radius is neglected to establish a cohesive law between multilayer parallelled graphenes and $\alpha$-alumina based on van der Waals 


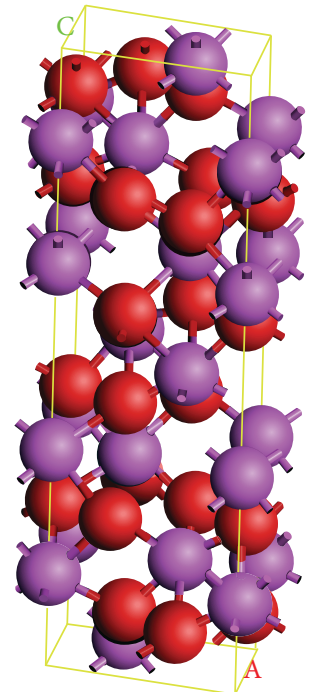

(a)

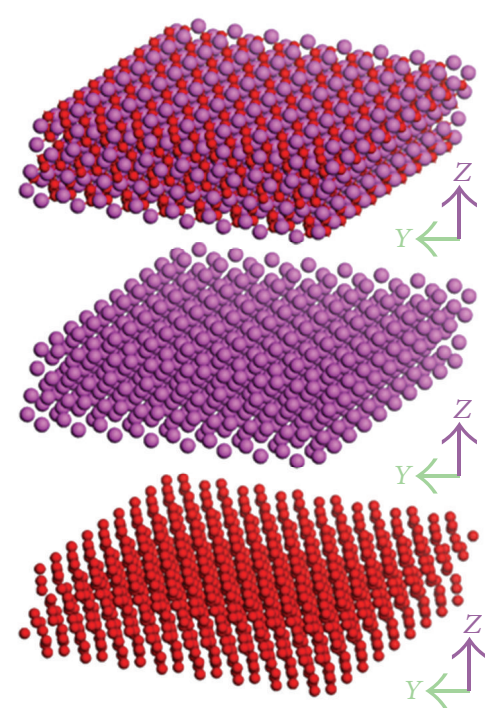

(b)

Figure 1: Crystal structure of $\alpha$-alumina. (a) The crystal structure cell, $a=0.4759 \mathrm{~nm}, b=0.4759 \mathrm{~nm}$, and $c=1.2991 \mathrm{~nm}$; (b) the crystal structure of $\alpha$-alumina, the oxygen atom cluster and aluminum atom cluster.

interactions. The stress distribution and the stress intensity are obtained by improved COX model. From cohesive low and COX model, the strain rate of nanotube-composite is given when the interfacial slip begins to occur through van der Waals interaction.

\section{The Stress Transfer Efficiency between SWCNTs and Matrix}

As the reinforcement of hard brittle material, such as Alumina, the weak connected effect of the interface between CNTs and $\alpha$-Alumina plays an important role. Generally, the interaction of atoms between CNTs and $\alpha$-alumina is provided by long-range potential, such as Lenard-Jones potential, as follows:

$$
V(r)=4 \varepsilon\left(\frac{\sigma^{12}}{r^{12}}-\frac{\sigma^{6}}{r^{6}}\right)
$$

where $V$ is the potential energy when the distance of two atoms is $r, \sqrt[6]{2} \sigma$ is the equilibrium distance between the atoms, and $\varepsilon$ is the bond energy at the equilibrium distance.

The crystal structure cell of $\alpha$-alumina is shown in Figure 1(a); the values of $\rho_{\mathrm{Al}}$ and $\rho_{\mathrm{O}}$ are obtained; $\varepsilon_{\mathrm{C}-\mathrm{O}}$ and $\varepsilon_{\mathrm{C}-\mathrm{Al}}$ can be achieved from $\varepsilon_{\mathrm{A}-\mathrm{B}}=\sqrt{\varepsilon_{\mathrm{A}} \varepsilon_{\mathrm{B}}}$, respectively. The crystal structure of $\alpha$-alumina was divided into two parts, oxygen atom cluster and aluminum atom cluster, as shown in Figure 1(b), and then we can analyze the cohesive model, respectively.

Using the RVE as shown in Figure 2(a), the different cohesive model is established from both nonboundary interface, Figure 2(b), and boundary interface, Figure 2(c), respectively; the cohesive energy is representative via van der Waals force.
For nonboundary interface,

$$
\begin{aligned}
\Phi= & \int_{-\infty}^{-h} 2 \pi \rho_{\mathrm{C}} \rho_{\mathrm{Al}_{2} \mathrm{O}_{3}} \varepsilon \sigma^{2}\left(\frac{2 \sigma^{10}}{5 z^{10}}-\frac{\sigma^{4}}{z^{4}}\right) d z \\
= & 2 \pi \rho_{\mathrm{C}} \rho_{\mathrm{Al}} \varepsilon_{\mathrm{C}-\mathrm{Al}} \sigma_{\mathrm{C}-\mathrm{Al}}{ }^{3}\left(\frac{\sigma_{\mathrm{C}-\mathrm{Al}}^{3}}{3 h^{3}}-\frac{2 \sigma_{\mathrm{C}-\mathrm{Al}}{ }^{9}}{45 h^{9}}\right) \\
& +2 \pi \rho_{\mathrm{C}} \rho_{\mathrm{O}} \varepsilon_{\mathrm{C}-\mathrm{O}} \sigma_{\mathrm{C}-\mathrm{O}}^{3}\left(\frac{\sigma_{\mathrm{C}-\mathrm{O}}^{3}}{3 h^{3}}-\frac{2 \sigma_{\mathrm{C}-\mathrm{O}}}{45 h^{9}}\right) .
\end{aligned}
$$

For boundary interface, the cohesive energy is obtained by a banding area of CNT.

Given $L$ is the overlapping length.

Consider

$$
\begin{aligned}
\Phi_{\mathrm{Line}}=\int_{-\infty}^{-h} 2 \pi \rho_{\mathrm{C}} \rho_{\mathrm{Al}} \varepsilon_{\mathrm{C}-\mathrm{Al}} \sigma_{\mathrm{C}-\mathrm{Al}}\left(\frac{2 \sigma_{\mathrm{C}-\mathrm{Al}}^{10}}{5 z^{10}}-\frac{\sigma_{\mathrm{C}-\mathrm{Al}}^{4}}{z^{4}}\right) L \\
\quad \times\left[1+\left(\frac{h^{4}}{L^{4}}\right)\right] d z \\
+\int_{-\infty}^{-h} 2 \pi \rho_{\mathrm{C}} \rho_{\mathrm{O}} \varepsilon_{\mathrm{C}-\mathrm{O}} \sigma_{\mathrm{C}-\mathrm{O}}\left(\frac{2 \sigma_{\mathrm{C}-\mathrm{O}}^{10}}{5 z^{10}}-\frac{\sigma_{\mathrm{C}-\mathrm{O}}^{4}}{z^{4}}\right) L \\
\quad \times\left[1+\left(\frac{h^{4}}{L^{4}}\right)\right] d z .
\end{aligned}
$$

Ignoring the higher order indefinite small value of (3), (2) and (3) have the same result of equilibrium spacing $h$ and can be given as

$$
h=0.429\left(\sigma_{\mathrm{C}-\mathrm{Al}}+\sigma_{\mathrm{C}-\mathrm{O}}\right) .
$$




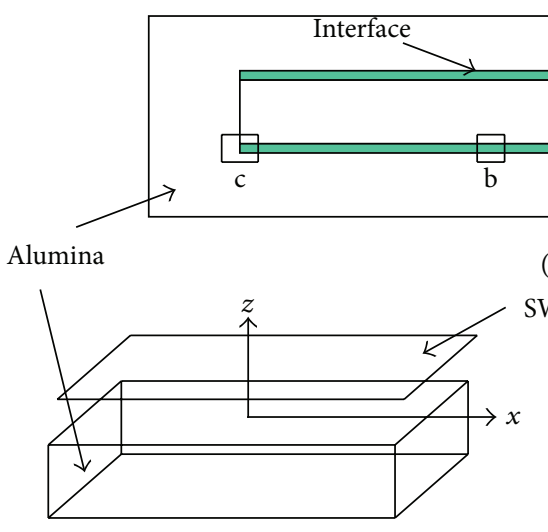

(b)

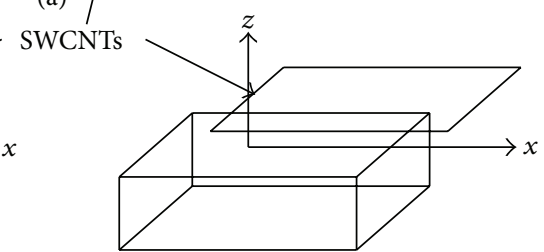

(c)

FIGURE 2: SWCNT-alumina composites. (a) Representative volume element, (b) nonboundary interface, and (c) boundary interface.

If a displacement $(u, v)$ is given, (2) and (3) are changed as

$$
\begin{aligned}
\Phi= & 2 \pi \rho_{\mathrm{C}} \rho_{\mathrm{Al}} \varepsilon_{\mathrm{C}-\mathrm{Al}} \sigma_{\mathrm{C}-\mathrm{Al}}^{3}\left(\frac{\sigma_{\mathrm{C}-\mathrm{Al}}^{3}}{3(h+v)^{3}}-\frac{2 \sigma_{\mathrm{C}-\mathrm{Al}}{ }^{9}}{45(h+v)^{9}}\right) \\
& +2 \pi \rho_{\mathrm{C}} \rho_{\mathrm{O}} \varepsilon_{\mathrm{C}-\mathrm{O}} \sigma_{\mathrm{C}-\mathrm{O}}^{3}\left(\frac{\sigma_{\mathrm{C}-\mathrm{O}}^{3}}{3(h+v)^{3}}-\frac{2 \sigma_{\mathrm{C}-\mathrm{O}}{ }^{9}}{45(h+v)^{9}}\right), \\
\Phi_{\text {line }}(u, v) & \\
= & 2 \pi \rho_{\mathrm{C}} \rho_{\mathrm{Al}} \varepsilon_{\mathrm{C}-\mathrm{Al}} \sigma_{\mathrm{C}-\mathrm{Al}}{ }^{3}\left(\frac{\sigma_{\mathrm{C}-\mathrm{Al}}{ }^{3}}{3(h+v)^{3}}-\frac{2 \sigma_{\mathrm{C}-\mathrm{Al}}{ }^{9}}{45(h+v)^{9}}\right)(L-u) \\
& +2 \pi \rho_{\mathrm{C}} \rho_{\mathrm{O}} \varepsilon_{\mathrm{C}-\mathrm{O}} \sigma_{\mathrm{C}-\mathrm{O}}^{3}\left(\frac{\sigma_{\mathrm{C}-\mathrm{O}}{ }^{3}}{3(h+v)^{3}}-\frac{2 \sigma_{\mathrm{C}-\mathrm{O}}{ }^{9}}{45(h+v)^{9}}\right)(L-u) .
\end{aligned}
$$

The partial derivatives of $(u, v)$ are easily deduced from (5) and (6), respectively. The normal stress of nonboundary and boundary interface is given as

$$
\begin{aligned}
\sigma_{\text {cohesive }}= & 2 \pi \rho_{\mathrm{C}} \rho_{\mathrm{Al}} \varepsilon_{\mathrm{C}-\mathrm{Al}} \sigma_{\mathrm{C}-\mathrm{Al}}^{2}\left(\frac{2 \sigma_{\mathrm{C}-\mathrm{Al}}^{10}}{5(h+v)^{10}}-\frac{\sigma_{\mathrm{C}-\mathrm{Al}}^{4}}{(h+v)^{4}}\right) \\
& +2 \pi \rho_{\mathrm{C}} \rho_{\mathrm{O}} \varepsilon_{\mathrm{C}-\mathrm{O}} \sigma_{\mathrm{C}-\mathrm{O}}{ }^{2}\left(\frac{2 \sigma_{\mathrm{C}-\mathrm{O}}^{10}}{5(h+v)^{10}}-\frac{\sigma_{\mathrm{C}-\mathrm{O}}{ }^{4}}{(h+v)^{4}}\right) .
\end{aligned}
$$

The shear stress of nonboundary interface is 0 . For boundary interface, the shear force of bonding area is given as

$$
\begin{aligned}
F_{\text {tangent }}= & \frac{\partial \Phi_{\text {line }}(u, v)}{\partial u} \\
= & 2 \pi \rho_{\mathrm{C}} \rho_{\mathrm{Al}} \varepsilon_{\mathrm{C}-\mathrm{Al}} \sigma_{\mathrm{C}-\mathrm{Al}}^{3}\left(\frac{2 \sigma_{\mathrm{C}-\mathrm{Al}}{ }^{9}}{45(h+v)^{9}}-\frac{\sigma_{\mathrm{C}-\mathrm{Al}}{ }^{3}}{3(h+v)^{3}}\right) \\
& +2 \pi \rho_{\mathrm{C}} \rho_{\mathrm{O}} \varepsilon_{\mathrm{C}-\mathrm{O}} \sigma_{\mathrm{C}-\mathrm{O}} 3\left(\frac{2 \sigma_{\mathrm{C}-\mathrm{O}}{ }^{9}}{45(h+v)^{9}}-\frac{\sigma_{\mathrm{C}-\mathrm{O}}{ }^{3}}{3(h+v)^{3}}\right) .
\end{aligned}
$$

So the average shear stress of boundary interface is given as

$$
\begin{aligned}
\tau_{\text {cohesive }}= & \frac{F_{\text {tangent }}}{L-u}=2 \pi \rho_{\mathrm{C}} \rho_{\mathrm{Al}} \varepsilon_{\mathrm{C}-\mathrm{Al}} \sigma_{\mathrm{C}-\mathrm{Al}}^{2} \\
& \times\left(\frac{2 \sigma_{\mathrm{C}-\mathrm{Al}}{ }^{9}}{45(h+v)^{9}}-\frac{\sigma_{\mathrm{C}-\mathrm{Al}}{ }^{3}}{3(h+v)^{3}}\right) \frac{\sigma_{\mathrm{C}-\mathrm{Al}}}{L-u} \\
& +2 \pi \rho_{\mathrm{C}} \rho_{\mathrm{O}} \varepsilon_{\mathrm{C}-\mathrm{O}} \sigma_{\mathrm{C}-\mathrm{O}}{ }^{2} \\
& \times\left(\frac{2 \sigma_{\mathrm{C}-\mathrm{O}}{ }^{9}}{45(h+v)^{9}}-\frac{\sigma_{\mathrm{C}-\mathrm{O}}{ }^{3}}{3(h+v)^{3}}\right) \frac{\sigma_{\mathrm{C}-\mathrm{O}}}{L-u},
\end{aligned}
$$

where $\rho_{\mathrm{C}}=4 / 3 \sqrt{3} l_{\mathrm{C}}{ }^{2}$ and $l_{\mathrm{C}}=0.142 \mathrm{~nm} . \rho_{\mathrm{Al}}=6.969 / \mathrm{nm}^{3}$ and $\rho_{\mathrm{O}}=6.195 / \mathrm{nm}^{3}$ are the volume density of aluminum and oxygen atoms number of alumina, respectively [14]. $\sigma_{\mathrm{C}-\mathrm{Al}}=$ $0.4028 \mathrm{~nm}, \sigma_{\mathrm{C}-\mathrm{O}}=0.392 \mathrm{~nm}[15], \varepsilon_{\mathrm{C}-\mathrm{Al}}=0.0038 \mathrm{ev}$, and $\varepsilon_{\mathrm{C}-\mathrm{O}}=0.0058 \mathrm{ev}[16]$.

The cohesive stress of the interface of CNTs and alumina is achieved by substituting the above parameters into (7) and (9), respectively. For short fiber reinforcement, there is only one free edge produced on each CNT's end, and the material can be supposed as an infinite along the $x$-axis. So the practical value of shear stress is only $1 / 2$ of the result of (9).

From Figures 3 and 4, we can find that the normal stress intensity of CNTs and alumina material is about $240 \mathrm{MPa}$, the average shear force of bounding area is about $27.5 \mathrm{MPa} \cdot \mathrm{nm}$, and the cohesive shear force is concentrated in CNTs' ends. The normal and shear stress intensity of the interface that is provided by van der Waals force can be achieved through the above analysis.

\section{Stress Distribution of CNTs and Alumina with Shear-Lag Model}

A RVE is taken from nanocomposites. Considering a perfect interfacial bonding, the COX model is changed by a hollow of 


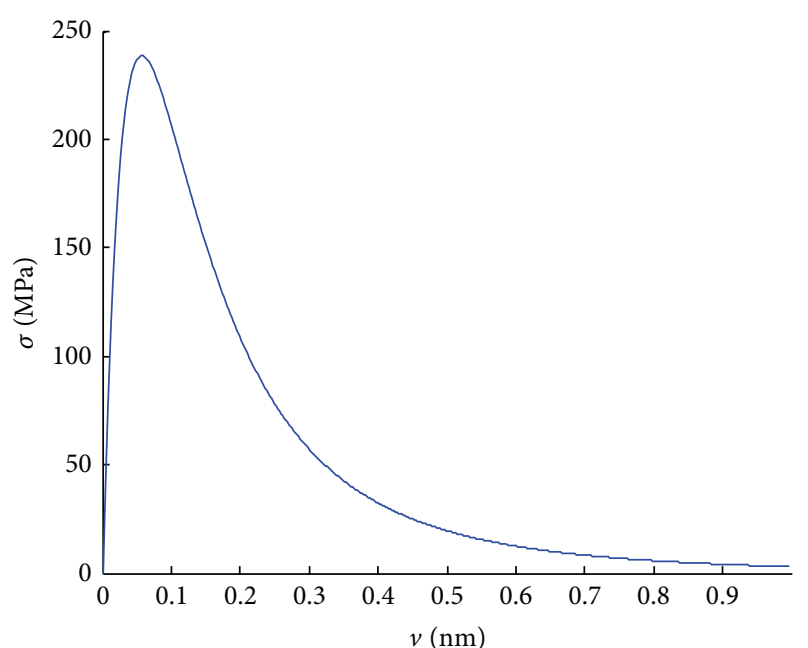

FIGURE 3: The relationship of normal stress and displacement based on van der Waals force.

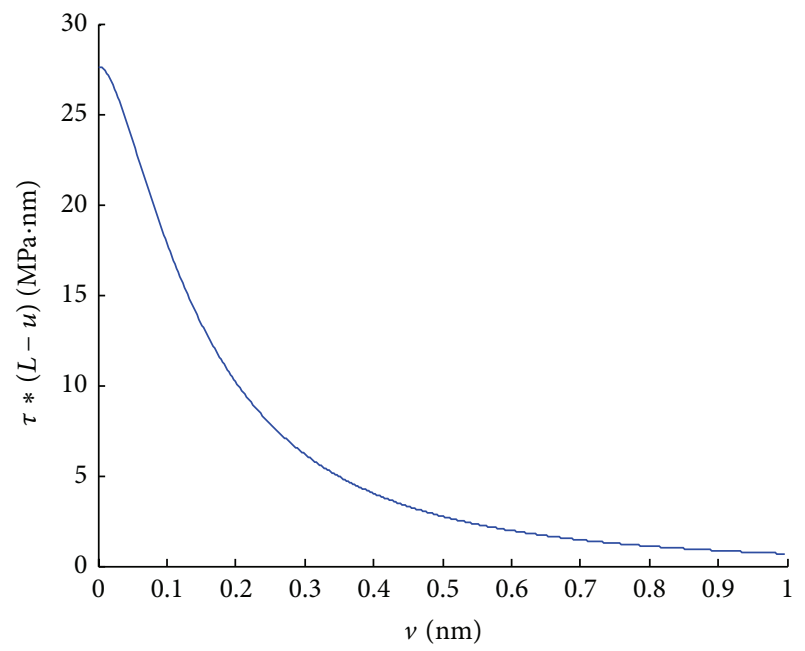

FIGURE 4: The relationship of shear stress and displacement based on van der Waals force.

SWCNTs, as shown in Figure 5. The stress of CNTs along tube length is $\sigma_{t}$ and the shear stress of interface is $\tau$ as follows:

$$
\begin{gathered}
\sigma_{t}=E_{t} e\left[1-\frac{\cosh \beta(L / 2-x)}{\cosh \beta(L / 2)}\right], \\
\tau=\frac{E_{t} e A_{t} \beta}{2 \pi r_{2}} \times \frac{\sinh \beta(L / 2-x)}{\cosh \beta(L / 2)}, \\
\beta=\sqrt{\left(\frac{G_{m}}{E_{t}}\right)\left(\frac{2 \pi}{A_{t} \ln \left(R / r_{2}\right)}\right)},
\end{gathered}
$$

where $e$ is the strain along CNT's length, $L$ is the length of CNT, $G_{m}$ is the shear modulus of matrix material, $E_{t}$ is Young's modulus of CNT, $R$ is the radius of RVE, $A_{t}=$ $\pi\left(r_{2}^{2}-r_{1}^{2}\right)$ is the cross-sectional area, and the value is $2.8413 \mathrm{~nm}^{2}$ with the parameters of $d=3 \mathrm{~nm}, r_{1}=1.16 \mathrm{~nm}$, and $r_{2}=1.5 \mathrm{~nm}$. The above formulae will reduce to the original COX model when the value of $r_{1}$ is zero.

In the following calculations, we take $E_{t}=1.0 \mathrm{TPa}, G_{m}=$ $143.44 \mathrm{GPa}$, and $e=0.0686 \%$, which is the ultimate strain of alumina material [17], and $R / r_{2}=7.236$ from $R / r_{2}=$ $\left(\pi / 4 V_{f}\right)^{1 / 2}$, where $V_{f}=1.5 \%$ is the volume content of CNTs in composites. $t=r_{2}-r_{1}$ is the thickness of CNTs, where $t=0.34 \mathrm{~nm}$.

Figure 6 shows the tensile stress distributions in various tube lengths. There is a maximum value when the length is longer than $30 \mathrm{~nm}$, and the value exists in the middle of CNTs. The shear stress of the interface between CNTs and alumina is concentrated in the end of CNTs. In the condition of the strain rate of material achieved to ultimate strain, the shear stress of CNTs beard is about $0.06 \mathrm{GPa}$. The shear stress distribution of the end is not effected by the length of CNTs (shown in Figure 7).

In order to compare to the maximum value that van der Waals force can afford, we make an integral of shear stress to the bonding area along the tube length as follows:

$$
F_{\text {line }}=\int_{0}^{L / 2} \tau d x
$$

And then

$$
F_{\text {line }}=28.69 \mathrm{MPa} \cdot \mathrm{nm}>27.5 \mathrm{MPa} \cdot \mathrm{nm} .
$$

Equation (14) shows that shear stress in perfect interfacial bonding is more beyond than that afforded by van der Waals force, and slipping has occurred. So the ultimate stress afforded by van der Waals force is defined as the static stress limit.

Substituting the result $F_{\text {line }}=27.5 \mathrm{MPa} \cdot \mathrm{nm}$ into (13), we can obtain a simulated result from (11) and (13); the strain limit of nanocomposites is taken out as follows:

$$
e_{1}=0.0091 \% \text {. }
$$

The tensile stress of CNTs and shear stress of interface are shown in Figures 8 and 9 when the strain rate is smaller than $0.0091 \%$.

Figure 10 shows the relationship between volume content of CNTs and tensile stress. Figure 10(a) shows that the tensile stress is decreasing with the increasing of radius of CNTs when the volume content is constant. Figure 10(b) shows that the maximum tensile stresses value can be achieved when the length of CNTs is longer than the effective length.

\section{Conclusions}

Based on multiscale method, the interfacial mechanical behavior of CNTs-alumina composites is analyzed. The interfacial stress is discussed by using cohesive law, which was reformed by using the crystal lattice of SWCNTs and $\alpha$ alumina. Based on van der Waals force, the maximum normal and shear stress are achieved, respectively. The tensile and shear stress distribution is achieved by using improved COX model. Giving a perfect interfacial bonding and long enough tube, there is a maximum value $(0.68 \mathrm{GPa})$ of tensile stress 

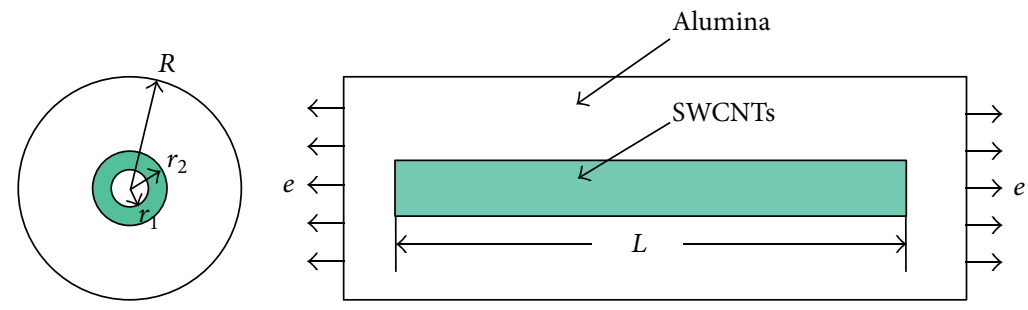

FIgURE 5: The RVE of SWCNTs reinforcement alumina composites.

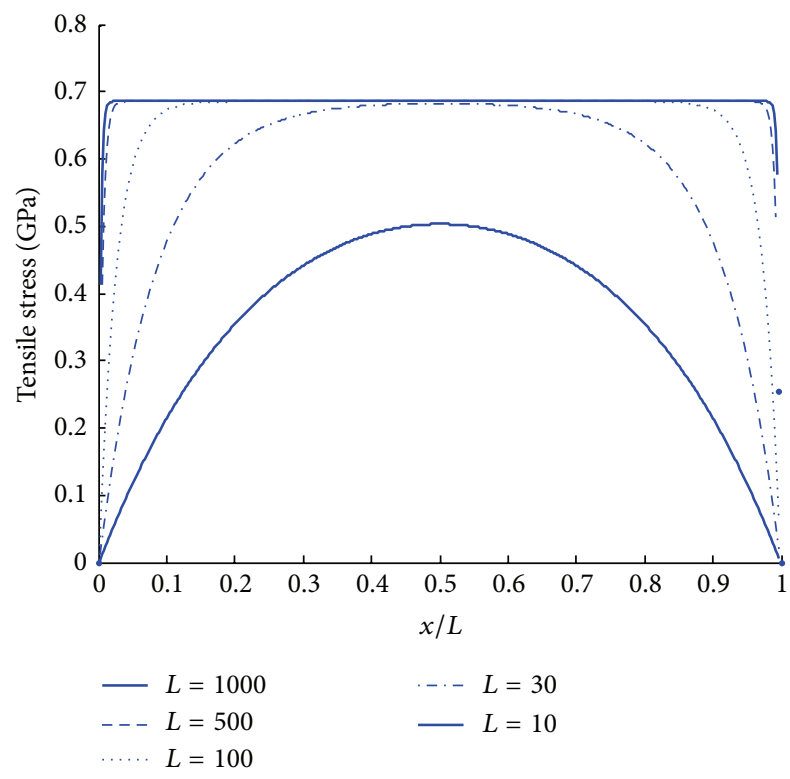

Figure 6: Tensile stress distributions at various tube lengths $(d=$ $3 \mathrm{~nm}, t=0.34 \mathrm{~nm})$.

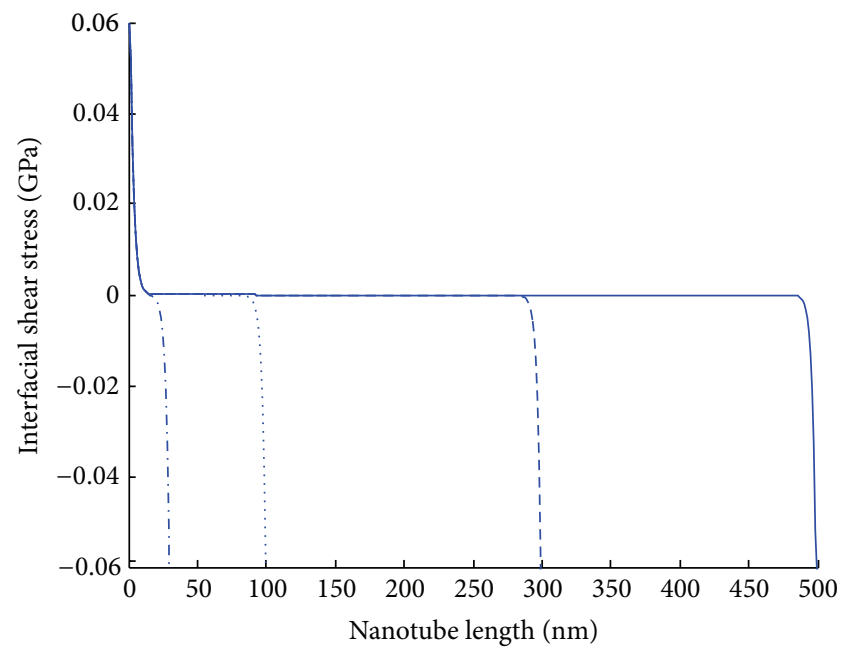

$$
\begin{aligned}
& -L=500 \\
& \text { - - } L=300 \\
& \text { … } L=100 \\
& \text {-..- } L=30
\end{aligned}
$$

FIGURE 7: Shear stress distribution at SWNT/alumina interface along the tube length $(d=3 \mathrm{~nm}, t=0.34 \mathrm{~nm})$.

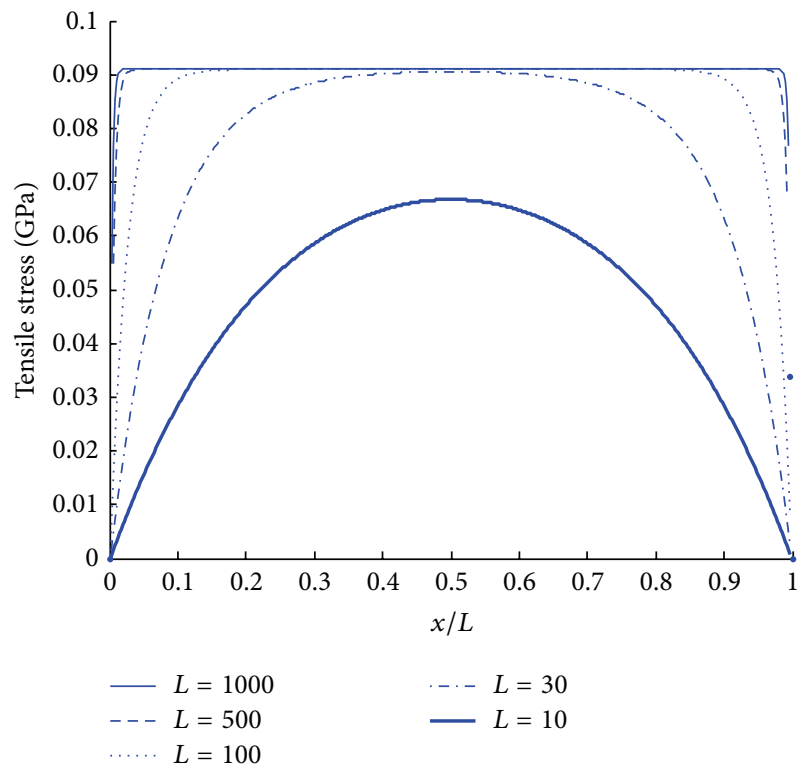

FIGURE 8: Tensile stress distributions at various tube lengths provided by van der Waals force $(d=3 \mathrm{~nm}, t=0.34 \mathrm{~nm})$.

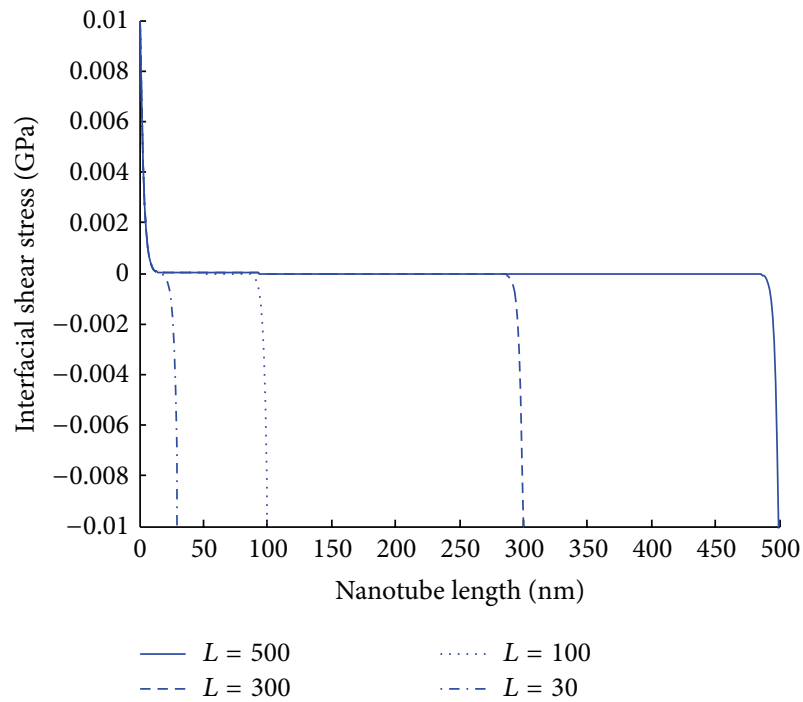

FIGURE 9: Shear stress at the SWNT/alumina interface along the tube length provided by van der Waals force $(d=3 \mathrm{~nm}, t=0.34 \mathrm{~nm})$. 


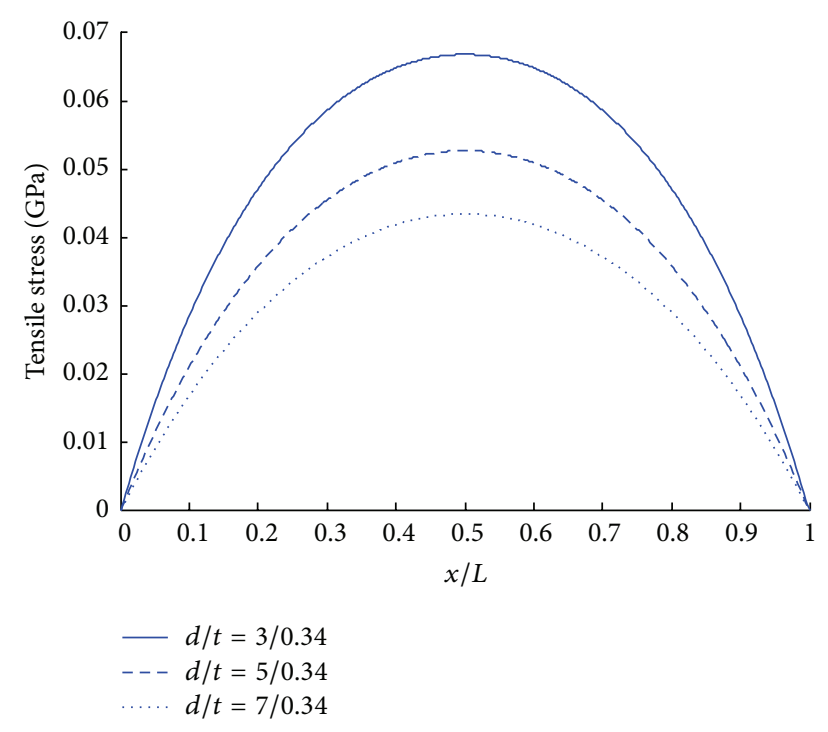

(a) $L=10 \mathrm{~nm}$

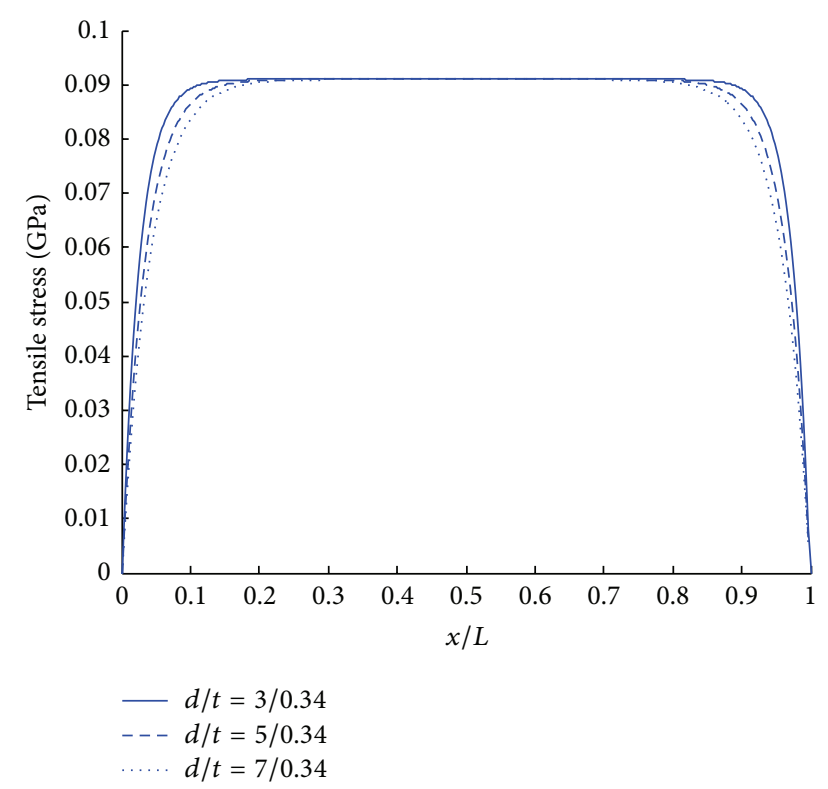

(b) $L=100 \mathrm{~nm}$

Figure 10: Effects of tube diameter $d$ on the tensile stress, (a) $L=$ $10 \mathrm{~nm}$ and (b) $L=100 \mathrm{~nm}$.

under the biggest strain $(0.686 \%)$ that the matrix can afford. The maximum value of shear stress exists in the end of CNTs. The integral of shear stress to the bonding area along the tube length is made and compared with the shear stress provided by van der Waals force. The result shows that the ultimate stress afforded by van der Waals interaction is achieved when the strain rate is $0.0091 \%$, and the interfacial slip begins to occur. The simple analysis is used as a basis of regulating suitable interaction to adapting to different situations.

\section{Conflict of Interests}

The authors declare that there is no conflict of interests regarding the publication of this paper.

\section{Acknowledgments}

The work is supported by the National Natural Science Foundation of China through Grant 11271234 and the Science Program of Shandong Provincial Education Department through Grant J13LJ51.

\section{References}

[1] I. Ahmad, H. Cao, H. Chen, H. Zhao, A. Kennedy, and Y. Q. Zhu, "Carbon nanotube toughened aluminium oxide nanocomposite," Journal of the European Ceramic Society, vol. 30, no. 4, pp. 865-873, 2010.

[2] J. Sun, L. Gao, and W. Li, "Colloidal processing of carbon nanotube/alumina composites," Chemistry of Materials, vol. 14, no. 12, pp. 5169-5172, 2002.

[3] M. Estili, A. Kawasaki, H. Sakamoto, Y. Mekuchi, M. Kuno, and T. Tsukada, "The homogeneous dispersion of surfactantless, slightly disordered, crystalline, multiwalled carbon nanotubes in $\alpha$-alumina ceramics for structural reinforcement," Acta Materialia, vol. 56, no. 15, pp. 4070-4079, 2008.

[4] C. N. He, F. Tian, and S. J. Liu, "A carbon nanotube/alumina network structure for fabricating alumina matrix composites," Journal of Alloys and Compounds, vol. 478, no. 1-2, pp. 816-819, 2009.

[5] S. C. Chowdhury and T. Okabe, "Computer simulation of carbon nanotube pull-out from polymer by the molecular dynamics method," Composites A: Applied Science and Manufacturing, vol. 38, no. 3, pp. 747-754, 2007.

[6] Y. L. Chen, B. Liu, X. Q. He, Y. Huang, and K. C. Hwang, "Failure analysis and the optimal toughness design of carbon nanotubereinforced composites," Composites Science and Technology, vol. 70, no. 9, pp. 1360-1367, 2010.

[7] S. Liu, N. Hu, G. Yamamoto et al., "Investigation on CNTS/alumina interface properties using molecular mechanics simulations," Carbon, vol. 49, pp. 3698-3704, 2011.

[8] L. Y. Jiang, Y. Huang, H. Jiang et al., "A cohesive law for carbon nanotube/polymer interfaces based on the van der Waals force," Journal of the Mechanics and Physics of Solids, vol. 54, no. 11, pp. 2436-2452, 2006.

[9] L. Y. Jiang, "Macroscopic behavior of carbon nanotube (CNT)reinforced composite accounting for interface cohesive force," Journal of Adhesion, vol. 86, no. 3, pp. 273-289, 2010.

[10] W. B. Lu, J. Wu, L. Y. Jiang, Y. Huang, K. C. Hwang, and B. Liu, "A cohesive law for multi-wall carbon nanotubes," Philosophical Magazine, vol. 87, no. 14-15, pp. 2221-2232, 2007.

[11] W. B. Lu, J. Wu, J. Song, K. C. Hwang, L. Y. Jiang, and Y. Huang, "A cohesive law for interfaces between multi-wall carbon nanotubes and polymers due to the van der Waals interactions," Science Direct, vol. 197, pp. 3261-3267, 2008.

[12] Y. Chen, K. Balani, and A. Agarwal, "Analytical model to evaluate interface characteristics of carbon nanotube reinforced aluminum oxide nanocomposites," Applied Physics Letters, vol. 92, no. 1, Article ID 011916, 2008.

[13] K. Q. Xiao and L. C. Zhang, "The stress transfer efficiency of a single-walled carbon nanotube in epoxy matrix," Journal of Materials Science, vol. 39, pp. 4481-4486, 2004.

[14] S. J. V. Frankland and V. M. Harik, "Analysis of carbon nanotube pull-out from a polymer matrix," Surface Science, vol. 525, no. 13, pp. L103-L108, 2003. 
[15] D. P. Li, J. M. Xie, H. Sun, S. Q. Wang, and Q. S. Du, "Quantum chemical study of molecular potential energies in methane hydrate structure-unit cell," Journal of Tianjin Normal University, vol. 25, no. 4, pp. 1-8, 2005.

[16] W. D. Cornell, P. Cieplak, C. I. Bayly et al., "A second generation force field for the simulation of proteins, nucleic acids, and organic molecules," Journal of the American Chemical Society, vol. 117, no. 19, pp. 5179-5197, 1995.

[17] Y. S. Yin, J. D. Jing et al., Alumina Ceramics and Composites, Chemical Industry Press, Peking, China, 2001. 

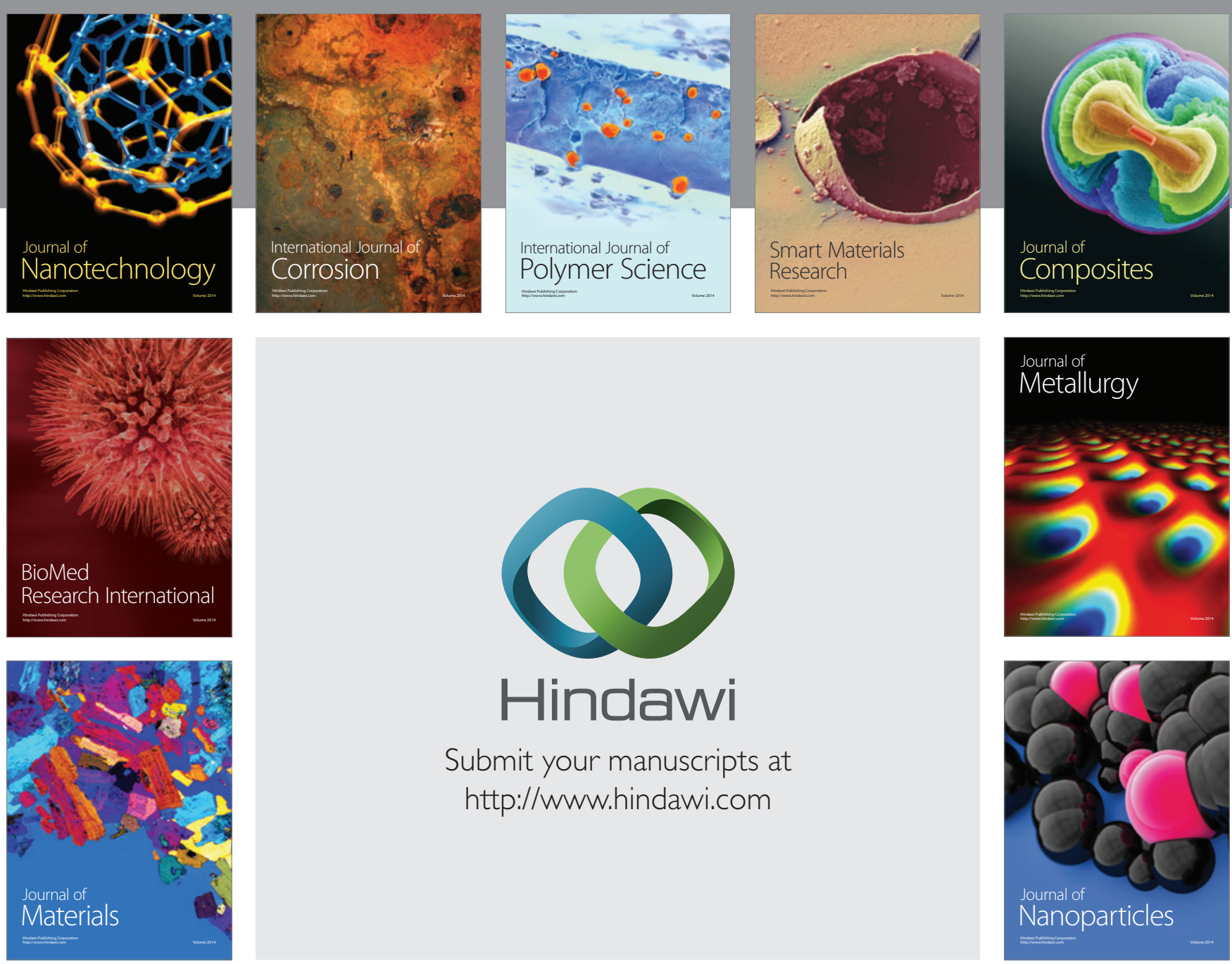

Submit your manuscripts at http://www.hindawi.com
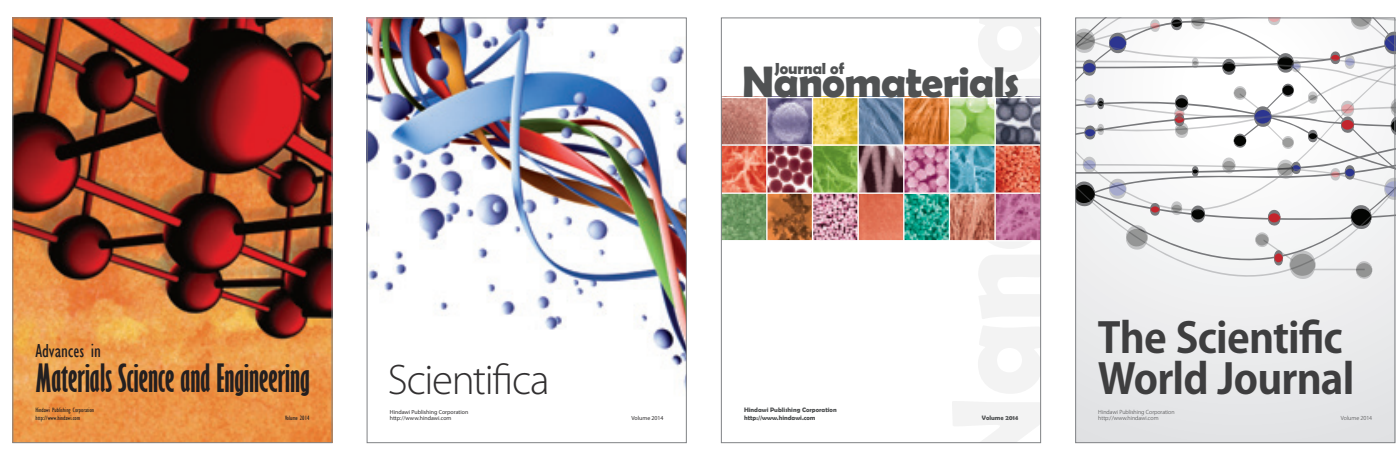

\section{The Scientific World Journal}
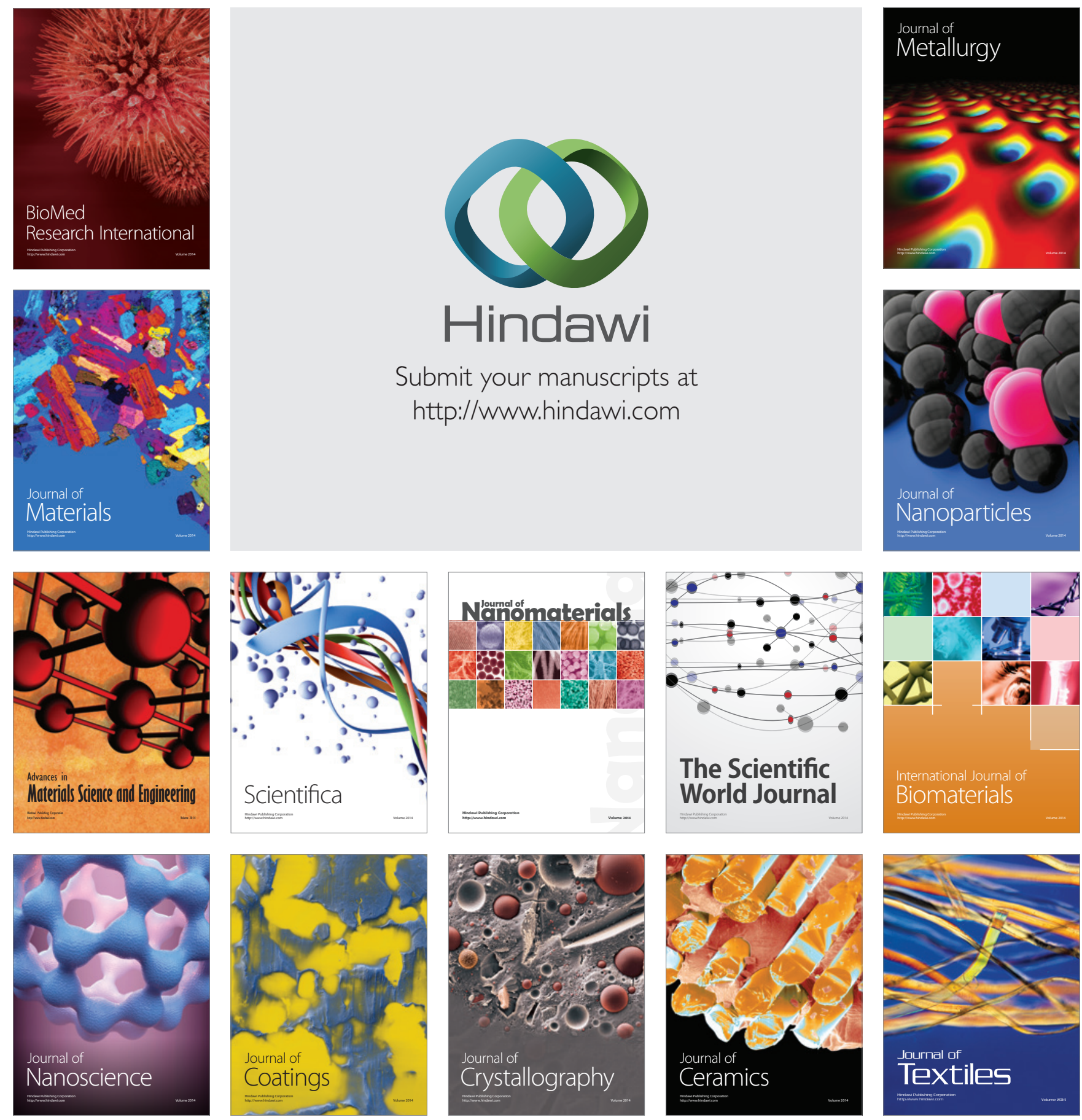